ISSN: 1410-8917

Jurnal Kimia

-Sains \&

Aplikasi

e-ISSN: 2597-9914
Jurnal Kimia Sains dan Aplikasi 20 (3) (2017): 136-139

Jurnal Kimia Sains dan Aplikasi Journal of Scientific and Applied Chemistry

Journal homepage: http://ejournal.undip.ac.id/index.php/ksa

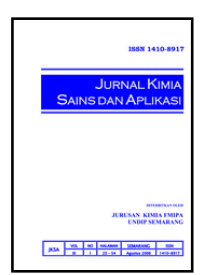

\title{
Sintesis Turunan Azomethin Sebagai Zat Aktif Inhibitor Korosi pada Logam Menggunakan Bahan Dasar Piperonal dan 2- Aminopiridin
}

\author{
Intan Endah Rachmawati ${ }^{\text {a }}$, Ngadiwiyana ${ }^{{ }^{*}}$, Ismiyarto ${ }^{\text {a }}$ \\ a Organic Chemistry Laboratory, Chemistry Department, Faculty of Sciences and Mathematics, Diponegoro University, Jalan Prof. \\ Soedarto, Tembalang, Semarang 50275 \\ * Corresponding author: ngadiwiyana@live.undip.ac.id
}

\begin{tabular}{l}
\hline Article Info \\
\hline Keywords: \\
azomethin, \\
corrosion \\
inhibition, weight \\
loss, corrosion rate
\end{tabular}

Kata kunci: azomethin, inhibitor korosi, weight loss, laju korosi

\begin{abstract}
Derivative compound synthesis from azomethin had been done through condensation reaction of piperonal and 2-aminopyridine by varying toluene, benzene, etanol solution for 3 hours. The result was characterized melting point and identified with UV-Vis spectroscopy, FTIR, and LC-MS. Corrosion inhibition activity test was done on iron by using weight loss method. Identification of UV-Vis spectra was observed a peak at 233 $\mathrm{nm}$ and FTIR proved azomethin group $(\mathrm{C}=\mathrm{N})$ wavenumber on $1604.77 \mathrm{~cm}^{-1}$, LC-MS showed molecule weight $226.26 \mathrm{gram} / \mathrm{mol}$ identical $\mathrm{N}$-(benzo[d][1,3]dioxol-5ylmethylene)pyridin-2-amine. Corrosion rate of $1 \%$ concentrated from derivative compound from azomethin was $1.2 \mathrm{mg} \mathrm{cm}^{-2}$ day ${ }^{-1}$ with 4 hour submerging time.
\end{abstract}

\section{Pendahuluan}

Salah satu kelemahan logam apabila dibiarkan di udara akan terjadi korosi akibat interaksi dengan oksigen. Selain itu, korosi suatu logam dipengaruhi oleh tingkat pencemaran udara, suhu, kelembaban, dan keberadaan zat-zat kimia yang bersifat korosif [1]. Korosi merupakan suatu reaksi redoks antara suatu logam dengan berbagai zat di lingkungannya yang mengakibatkan penurunan mutu logam tersebut. Korosi dapat dicegah dengan mengubah besi menjadi baja tahan karat (stainless steel), pelapisan (coating), proteksi katodik, dan dapat pula dicegah menggunakan senyawa inhibitor korosi [2].

Senyawa inhibitor korosi merupakan suatu zat yang apabila ditambahkan dalam lingkungan yang korosif dapat menurunkan laju korosi. Senyawa inhibitor korosi pada logam jenisnya ada dua, yaitu anorganik dan organic [3]. Fosfat, kromat, dikromat, silikat, borat, tungstat, molibdat dan arsenat adalah beberapa senyawa anorganik yang digunakan sebagai senyawa inhibitor korosi pada logam. Senyawa inhibitor korosi organik adalah senyawa heterosiklik yang mengandung 
atom nitrogen, sulfur atau oksigen yang mempunyai pasangan elektron bebas [4]. Senyawa inhibitor korosi yang paling efektif adanya senyawa inhibitor organik [5]. Hal ini disebabkan karena senyawa organik yang mengandung atom $\mathrm{N}, \mathrm{S}, \mathrm{O}$ memiliki pasangan elektron bebas pada sistem rantai aromatiknya yang dapat berikatan dengan muatan positif logam sehingga terjadi adsorpsi antara permukaan logam dengan inhibitor [6]. Salah satu senyawa inhibitor organik adalah senyawa azomethin.

Senyawa azomethin merupakan hasil reaksi kondensasi antara aldehid dan amina. Aldehid aromatik dan amina primer akan menghasilkan senyawa azomethin yang stabil karena akan menghasilkan produk dengan cincin aromatik dan ikatan rangkap yang terkonjugasi [7]). Hania [8] telah melakukan penelitian dan berhasil mensintesis senyawa azomethin menggunakan bahan dasar 2-aminopiridin dan benzaldehid, reaksi ini melalui perefluksan selama dua jam dengan pelarut toluen dan dihasilkan produk dengan rendemen $75,6 \%$ dan titik leleh $92-95{ }^{\circ} \mathrm{C}$. Senyawa azomethin merupakan senyawa dengan gugus fungsi $-\mathrm{C}=\mathrm{N}-$ yang mempunyai potensi sebagai inhibitor korosi [9]. Dilihat dari potensinya sebagai senyawa inhibitor korosi, maka penelitian tentang senyawa turunan azomethin perlu dikembangkan. Sehingga dapat mempunyai aktivitas yang lebih stabil

Dalam penelitian ini dilakukan sintesis senyawa turunan azomethin dari piperonal dan 2-aminopiridin yang mempunyai aktivitas sebagai zat aktif inhibitor korosi pada logam. Dalam sintesis senyawa turunan azomethin ini dilakukan variasi pelarut, yaitu toluen, benzen dan etanol. Sintesis senyawa turunan azomethin perlu ditentukan pelarut yang tepat untuk menghasilkan produk sintesis yang optimal, sehingga diperoleh rendemen yang optimal.

\section{Metodologi Penelitian}

Bahan yang digunakan dalam penelitian ini adalah 2-Aminopiridin $99 \%$ (Aldrich), piperonal p.a, etanol p.a, toluen p.a, benzen p.a, asam asetat p.a, $\mathrm{HCl} 2 \mathrm{~N}$, logam besi ukuran panjang $3 \mathrm{~cm}$, lebar $1 \mathrm{~cm}$ dan tebal $0,52 \mathrm{~mm}$, aseton.Alat yang digunakan dalam penelitian adalah seperangkat alat refluks yang dilengkapi peralatan gelas, seperangkat alat destilasi fraksinasi penurunan tekanan dilengkapi peralatan gelas, seperangkat alat titik leleh Barnstead International 2555 KERPER BLVD, spektrometer UV-Vis (SHIMADZU), FTIR (SHIMADZU), LC-MS Hitachi L 6200.

\section{Prosedur Penelitian}

\section{Sintesis senyawa turunan azomethin}

Piperonal sebanyak 2,957 g (0,0197 mol) dilarutkan dalam $20 \mathrm{~mL}$ toluen. Pelarutan dilakukan dalam labu leher tiga volume $150 \mathrm{~mL}$ yang dilengkapi dengan pendingin, pengaduk magnetik dan termometer. Setelah piperonal larut, ditambahkan 1,853 g (0,0197 mol) 2aminopiridin kemudian direfluks selama 3 jam pada suhu refluks sampai larutan homogen. Campuran kemudian disaring dan kristal yang terbentuk dikeringkan. Hal yang sama dilakukan dalam pelarut benzen. Pada pelarut etanol dilakukan pemurnian campuran hasil refluks dengan destilasi fraksinasi penurunan tekanan. Kristal yang diperoleh ditimbang dan diukur tititk lelehnya. Kemudian dianalisis menggunakan spektrometer UV-Vis, FTIR dan LC-MS.

\section{Uji Aktivitas Inhibitor Korosi pada Logam Besi}

Pengujian inhibitor korosi senyawa turunan azomethin dilakukan berdasarkan metode weight loss pada logam besi dalam larutan $\mathrm{HCl} 2 \mathrm{~N}$. Variabel yang diukur dalam metode ini adalah waktu pencelupan logam besi. Dalam metode ini digunakan logam besi yang belum berkarat. Logam tersebut dibersihkan dengan emery paper dan dicuci dengan aseton, kemudian logam dikeringkan dalam temperatur ruang. Kemudian logam besi ditimbang untuk mengetahui berat awal.

Logam besi yang dilapisi dengan larutan inhibitor berupa senyawa turunan azomethin selama dua hari dan logam besi tanpa dilapisi inhibitor kemudian dilakukan pencelupan pada larutan $\mathrm{HCl} 2 \mathrm{~N}$ dalam botol fial yang berbeda pada temperatur ruang. Lama pencelupan dalam larutan $\mathrm{HCl} 2 \mathrm{~N}$ dilakukan dengan variasi lama waktu pencelupan yaitu selama 4 jam; 6 jam; 1 hari; dan 4 hari. Kemudian logam dikeringkan dan dihitung efisiensi inhibitor dan laju korosi terhadap logam besi.

\section{Hasil dan Pembahasan}

\section{Sintesis Senyawa turunan azomethin}

Sintesis ini dilakukan dengan variasi pelarut yaitu toluene, benzen dan etanol. Hal ini bertujuan untuk mengetahui pengaruh perbedaan kelarutan tehadap rendemen produk yang diperoleh. Setelah bereaksi, campuran yang diperoleh disaring akan diperoleh filtrat dan kristal. Hasil kristal yang diperoleh dikeringkan pada suhu kamar, kemudian ditimbang dan ditentukan titik lelehnya. Pada sintesis menggunakan pelarut etanol, setelah bereaksi campuran yang diperoleh tidak langsung disaring karena belum menunjukkan adanya produknya berupa kristal. Untuk mendapatkan kristal harus dilakukan pemurnian dengan destilasi fraksinasi penurunan tekanan. Hal ini dilakukan karena hasil refluks dengan pelarut etanol masih tetap berupa cairan. Etanol merupakan pelarut yang cenderung bersifat asam, $\mathrm{H}^{+}$pada etanol akan menyerang elektron bebas pada 2-aminopiridin dan terbentuk garam amonium. Perlu dilakukan vakum untuk memisahkan etanol dan produk. Digunakan variasi pelarut toluen, benzen dan etanol untuk mengetahui perngaruh keasaman pelarut terhadap reaksi yang terjadi. Dilihat dari sifat keasaman atau kemampuan melepas proton dari ketiga pelarut tersebut etanol bersifat paling asam. Etanol merupakan pelarut protik yang berperan sebagai donor proton dan akan mempercepat pelepasan $\mathrm{H}_{2} \mathrm{O}$ dalam reaksi eliminasi sehingga reaksi berjalan cepat dan diperoleh rendemen yang banyak. Sifat keasaaman dari ketiga pelarut adalah etanol $>$ toluen $>$ benzen. Dari tabel IV.1 dapat dilihat bahwa hasil sintesis dengan pelarut benzen mempunyai rendemen yang paling tinggi, yaitu sebesar $70,59 \%$, pelarut etanol mempunyai rendemen paling 
rendah, sebesar 29,70\%, ini disebabkan bahan dasar 2aminopiridin bersifat higroskopis sehingga akan mengadakan ikatan hidogen dengan proton dari etanol hal ini menunjukkan reaksi yang berjalan tidak sempurna.

Hasil produk sintesis senyawa turunan azomethin terlebih dahulu dianalisis awal menggunakan spektroskopi UV-Vis. Hasil analisis UV-Vis dapat dilihat pada gambar 1.

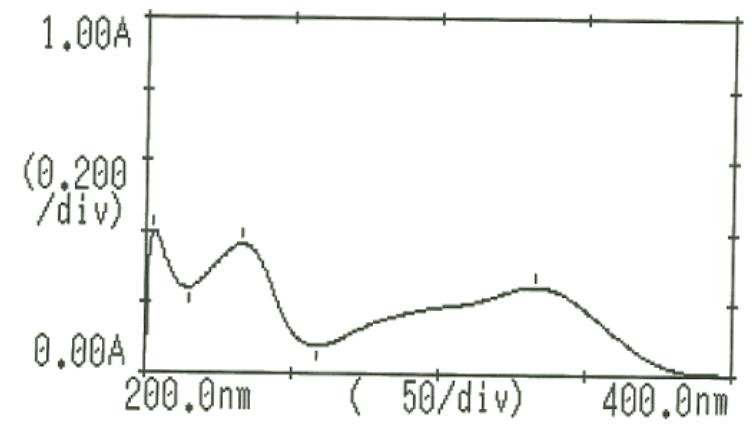

Gambar 1. Analisis UV-Vis Hasil sintesis dengan pelarut benzen

Dari gambar 1 dapat dilihat adanya puncak serapan $233 \mathrm{~nm}$ menunjukkan adanya gugus $\mathrm{C}=\mathrm{N}$ (azomethin) [10]. Identifikasi menggunakan LC-MS ditunjukkan oleh kromatogram dan spectrogram senyawa turunan azomethin dapat dilihat pada gambar 2.

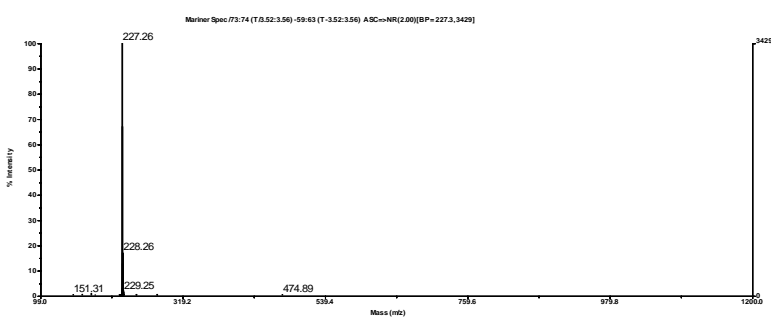

Gambar 2. Spektogram senyawa senyawa turunan azomethin

Dari gambar 2 memperlihatkan memperlihatkan berat molekul pada $\mathrm{m} / \mathrm{z} 227,26[\mathrm{M}+\mathrm{H}]^{+}$. Hal ini menunjukkan bahwa berat molekul senyawa hasil sintesis adalah $227,26-1=226,26$ yang mengidikasikan berat molekul m/z 226,26 $\left[\mathrm{M}^{+}\right]$yang identik dengan struktur $\mathrm{N}$-(benzo[d][1,3]dioxol-5ylmethylene)pyridin-2-amin $\left(\mathrm{C}_{13} \mathrm{H}_{10} \mathrm{~N}_{2} \mathrm{O}_{2}\right)$.

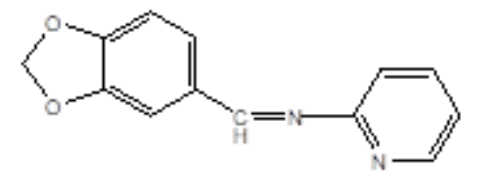

Gambar 3 Struktur N-(benzo[d][1,3]dioxol-5ylmethylene)pyridin-2-amine

Karakterisasi menggunakan FTIR dapat diihat ada gambar 4 .

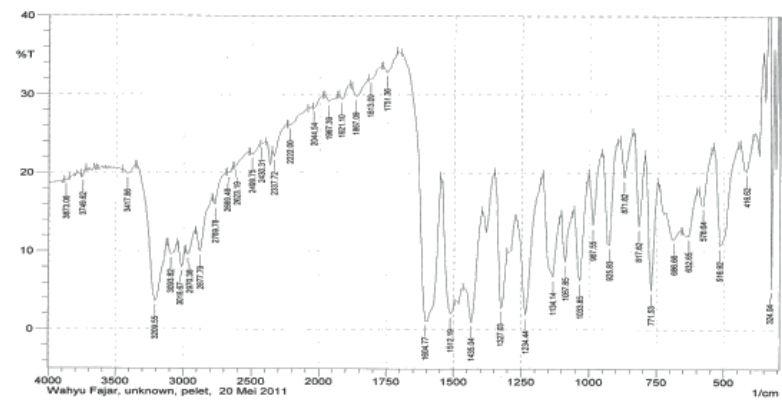

Gambar 4. Spektra FTIR N-(benzo[d][1,3]dioxol-5ylmethylene)pyridin-2-amine

Panjang gelombang penting dari spektra FTIR N(benzo[d][1,3]dioxol-5-ylmethylene)pyridin-2-amine) dapat dilihat pada tabel 1.

Tabel 1. Bilangan gelombang spektra FTIR N(benzo[d][1,3]dioxol-5-ylmethylene)pyridin-2-amine

\begin{tabular}{ll}
\hline Jenis vibrasi & Panjang gelombang \\
\hline azomethin $(\mathrm{C}=\mathrm{N})$ & $1604,77 \mathrm{~cm}^{-1}$ \\
\hline Vibrasi $\left(\mathrm{C}_{\mathrm{sp} 2}-\mathrm{H}\right)$ & $3093,82 \mathrm{~cm}^{-1}$ \\
\hline $\mathrm{C}=\mathrm{C}$ aromatik & $1512,19 \mathrm{~cm}^{-1}$ \\
\hline $\begin{array}{l}\text { Subtitusi benzen posisi } \\
\text { orto }\end{array}$ & $771,53 \mathrm{~cm}^{-1}$ \\
\hline $\begin{array}{l}\text { Subtitusi benzen posisi } \\
\text { para }\end{array}$ & $817,82 \mathrm{~cm}^{-1}, 871,82 \mathrm{~cm}^{-1}$ \\
\hline Vibrasi C-O & $1234,44 \mathrm{~cm}^{-1}$ \\
\hline $\begin{array}{l}\text { Vibrasi } \mathrm{C}_{\mathrm{sp} 3}-\mathrm{H} \text { dari } \\
\text { gugus metilen }\end{array}$ & $2970,38 \mathrm{~cm}^{-1}$ diperkuat \\
\hline
\end{tabular}

Uji Aktivitas Inhibitor Korosi pada Logam Besi

Pengaruh penambahan inhibitor hasil sintesis ( $N$ (benzo[d][1,3]dioxol-5-ylmethylene)pyridin-2-amine) terhadap laju korosi logam besi dapat ditentukan melalui metode pengurangan berat (weight loss), yaitu dengan menghitung selisih berat besi sebelum dan sesudah direndam dalam larutan tanpa dan dengan penambahan inhibitor produk sintesis (Dwi dan Harmami, 2009). Senyawa $N-\left(\right.$ benzo $[d][1,3]$ dioxol $-5^{-}$ ylmethylene)pyridin-2-amine disiapkan dalam beberapa konsentrasi, yaitu 0,06 \%, 0,12 \%, 0,25\%, 0,05\% dan $1,00 \%$ dengan perendaman dalam larutan inhibitor selama 4 jam, 6 jam, 1 hari dan 4 hari. Nilai laju korosi dapat dilihat pada tabel 2.

Tabel 2. Laju korosi logam besi pada variasi konsentrasi inhibitor $N$-(benzo[d] $[1,3]$ dioxol-5-ylmethylene) pyridin2-amine

\begin{tabular}{ccccc}
\hline \multirow{2}{*}{ konsentrasi (\%) } & \multicolumn{4}{c}{ Laju Korosi $\left(\mathrm{mg} \mathrm{cm}^{-2}\right.$ hari $\left.^{-1}\right)$} \\
\cline { 2 - 5 } & 4 jam & 6 jam & 1 hari & 4 hari \\
\hline 0,00 & 1,40 & 4,13 & 4,23 & 5,81 \\
0,06 & 2,20 & 2,53 & 4,33 & 4,98 \\
0,12 & 2,00 & 2,80 & 3,73 & 2,21 \\
0,25 & 2,20 & 1,38 & 4,60 & 5,15 \\
0,50 & 3,20 & 2,66 & 4,63 & 5,61 \\
1,00 & 1,20 & 2,40 & 3,43 & 4,90 \\
\hline
\end{tabular}


Konsentrasi efektif senyawa turunan azomethin sebagai inhibitor korosi ditunjukkan pada konsentrasi 1 $\%$ dengan laju korosi yang mampu menghambat sampai $1,2 \mathrm{mg} \mathrm{cm}^{-2}$ hari $^{-1}$ pada perendaman selama 4 jam dan efisiensi inhibitor sebesar 14,28\%. Berdasarkan Tabel 2 dapat dilihat setelah penambahan larutan inhibitor produk sintesis terjadi kenaikan dan penurunan laju korosi pada logam besi. Hal ini menunjukkan bahwa kemampuan inhibisi larutan inhibitor produk sintesis kurang maksimal, karena proses adsorpsi yang kurang merata pada permukaan logam. Menurut Faya [1], berdasarkan proses adsorpsi pada permukaan logam, semakin besar konsentrasi larutan inhibitor maka laju korosi akan semakin kecil [4].

\section{Kesimpulan}

Senyawa turunan azomethin, $N-$ (benzo[d] $[1,3]$ dioxol5-ylmethylene)pyridin-2-amine dari piperonal dan 2aminopiridin. Pengaruh pelarut benzen pada suhu $84{ }^{\circ} \mathrm{C}$ menghasilkan produk optimal yaitu 70,59 \% dan titik leleh $92,5-95,1{ }^{\circ} \mathrm{C}$. Senyawa $N$-(benzo[d][1,3]dioxol-5ylmethylene)pyridin-2-amine mempunyai aktivitas sebagai inhibitor korosi dengan laju korosi optimum sebesar 1,2 $\mathrm{mg} \mathrm{cm}^{-2}$ hari $^{-1}$ dengan waktu perendaman 4 jam dan efisiensi inhibitor sebesar $14,28 \%$ pada konsentrasi $1 \%$.

\section{Daftar Pustaka}

[1] Lidya Faya Pengaruh inhibitor natrium hidrogen fosfat terhadap laju korosi baja dalam air laut, Jurusan Kimia, Universitas Diponegoro, Semarang

[2] Kenneth R. Trethewey, John Chamberlain, Korosi : Untuk Mahasiswa Sains dan Rekayasa, A.T.K. Widodo, Gramedia, Jakarta, 1991.

[3] Mars Guy Fontana, Corrosion engineering, Tata McGraw-Hill Education, 2005.

[4] Nnabuk O Eddy, Stanislav R Stoyanov, Eno E Ebenso, Fluoroquinolones as corrosion inhibitors for mild steel in acidic medium; experimental and theoretical studies, International Journal of Electrochemical Science, 5, (2010) 1127-1150

[5] Rosita Dwi, M Harmami, Studi Inhibisi Korosi Baja Austenitik 304 dalam Media $\mathrm{NaCl}$ 3\% dengan Menggunakan Inhibitor Asam-Asam Lemak Hasil Hidrolisis Minyak Biji Kapuk, Jurusan Kimia, Institut Teknologi Sepuluh Nopember, Surabaya

[6] P. Matheswaran, A. K. Ramasamy, A Study of Mild Steel Corrosion Using Adhatoda Vasica (AV) Extract as Inhibitor in Different Acid Medium, E-Journal of

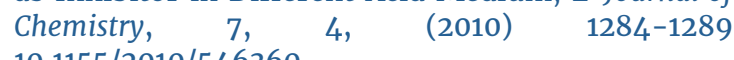
$10.1155 / 2010 / 546360$

[7] Ralph J. Fessenden, Joan S. Fessenden, Kimia Organik A.H. Pudjaatmaka, Erlangga, Jakarta, 1994.

[8] Majed M. Hania, Synthesis of Some Imines and Investigation of their Biological Activity, E-Journal of Chemistry, 6, 3, (2009) 629-632 http://dx.doi.org/10.1155/2009/104058

[9] Mrunalini M. Deshpande, Subhash B. Junne, Devdatta V. Saraf, Prafullakumar A. Kulkarni, Synthesis and spectral analysis of some new lanthanide complexes derived from 2,4 and 2,5- dihydroxy acetophenones and screened their antimicrobial activity, Journal of Chemical and Pharmaceutical Research, 2, 3, (2010) 453-458

[10] Robert M. Silverstein, Francis X. Webster, David J. Kiemle, David L. Bryce, Spectrometric Identification of Organic Compounds, 5 ed., John Wiley and Sons Inc., New York, 1991. 